\title{
Lipidic nanocapsule drug delivery: neuronal protection for cochlear implant optimization
}

This article was published in the following Dove Press journal:

International Journal of Nanomedicine

14 May 2012

Number of times this article has been viewed

\section{Hartwig Meyer ${ }^{1,2}$ \\ Timo Stöver ${ }^{1,3}$ \\ Florian Fouchet ${ }^{4}$ \\ Guillaume Bastiat ${ }^{4}$ \\ Patrick Saulnier ${ }^{4}$ \\ Wolfgang Bäumer ${ }^{2}$ \\ Thomas Lenarz' \\ Verena Scheper'}

'Department of Otolaryngology, Hannover Medical School, ${ }^{2}$ Institute for Pharmacology, Toxicology and Pharmacy, University of

Veterinary Medicine Hannover, Hannover, Germany; ${ }^{3}$ Department of Otolaryngology, Johann Wolfgang Goethe University, Frankfurt, Germany; ${ }^{4}$ Laboratoire d'Ingénierie de la Vectorisation Particulaire, University of Angers, Angers, France

Correspondence: Verena Scheper Department of Otolaryngology, Carl-Neuberg-Str. I, Hannover Medical School, 30625 Hannover, Germany Tel +495II 5324369

Fax +495II 5323293

Email scheper.verena@mh-hannover.de
Objective: Sensorineural hearing loss leads to the progressive degeneration of spiral ganglion cells (SGC). Next to postoperative fibrous tissue growth, which should be suppressed to assure a close nerve-electrode interaction, the density of healthy SGC is one factor that influences the efficiency of cochlear implants (CI), the choice of treatment for affected patients. Rolipram, a phosphodiesterase- 4 inhibitor, has proven neuroprotective and anti-inflammatory effects and might also reduce SGC degeneration and fibrosis, but it has to pass the cellular membrane to be biologically active.

Methods: Lipidic nanocapsules (LNC) can be used as biodegradable drug carriers to increase the efficacy of conventional application methods. We examined the biological effects of rolipram and LNC's core encapsulated rolipram on SGC and dendritic cell (DC) tumor necrosis factor- $\alpha$ (TNF- $\alpha)$ production in vitro and on SGC survival in systemically-deafened guinea pigs in vivo.

Results: Our results prove that rolipram does not have a beneficial effect on cultured SGC. Incorporation of rolipram in LNC increased the survival of SGC significantly. In the DC study, rolipram significantly inhibited TNF- $\alpha$ in a dose-dependent manner. The rolipram-loaded LNC provided a significant cytokine inhibition as well. In vivo data do not confirm the in vitro results.

Conclusion: By transporting rolipram into the SGC cytoplasm, LNC enabled the neuroprotective effect of rolipram in vitro, but not in vivo. This might be due to dilution of test substances by perilymph or an inadequate release of rolipram based on differing in vivo and in vitro conditions. Nevertheless, based on in vitro results, proving a significantly increased neuronal survival when using LNC-rolipram compared to pure rolipram and pure LNC application, we believe that the combination of rolipram and LNC can potentially reduce neuronal degeneration and fibrosis after $\mathrm{CI}$ implantation. We conclude that rolipram is a promising drug that can be used in inner ear therapy and that LNC have potential as an inner ear drug-delivery system. Further experiments with modified conditions might reveal in vivo biological effects.

Keywords: rolipram, nanoparticle, hearing loss, spiral ganglion cell, inner ear

In industrialized nations, sensorineural hearing loss is a common disease and is usually caused by a primary loss of auditory hair cells, which are the inner ear's sensory cells. In addition to hereditary factors, acquired causes, such as increased noise exposure or the application of ototoxic drugs, play a crucial role in the development of sensorineural hearing loss. ${ }^{1,2}$

An effective treatment for damaged hair cells or for the regeneration of already degenerated sensory cells of the inner ear in humans is not yet possible. Instead, the 
prosthetic forms of therapy are performed to replace the damaged organ's function. Severely impaired and deaf patients are treated by implantation of electronic inner ear prostheses called cochlear implants. Deaf patients treated with cochlear implants gain a renewed sense of hearing and have a greater opportunity to communicate using audible speech. ${ }^{3}$ This leads to improved social integration and a significant increase in the patient's quality of life.

Cochlear implants use a multichannel electrode that is inserted into the scala tympani to replace the function of the missing hair cells. Through the formation and transmission of spiral ganglion cell (SGC) action potentials, an artificially-generated sound impression is achievable. However, following the primary loss of hair cells, a progressive decrease in SGC density is observed. ${ }^{4}$ This is caused by missing electrical and neurotrophic stimulation, as well as other forms of stimulation., ${ }^{5,6}$ To achieve better speech recognition with cochlear implants, a high number of SGC must be ensured. ${ }^{6}$

A large number of neurotrophic factors have a protective effect on SGC after primary hair cell loss. The systemic treatment of inner ear diseases is complicated by the presence of the blood-cochlear barrier. Adequate drug levels are only reached through the application of very high drug doses, which leads to an increased risk of side effects. Through local application of neurotrophic factors, the progressive degeneration of SGC may be decreased. Important representatives of this substance group are brain-derived neurotrophic factor (BDNF), glial cell line-derived neurotrophic factor, and fibroblast growth factor. ${ }^{78}$ Nevertheless, continuous therapy is necessary because previous studies detected a progressive reduction of SGC after the cessation of therapeutical application of BDNF. ${ }^{9}$ The first attempts to produce continuous drug-delivery systems were realized using osmotic pumps. These pumps allowed continuous application periods into the inner ear for weeks. Because of delivery time limitations and the necessity of pump changes that would allow for longer application duration, this approach is not feasible for human therapeutic applications.

Another option for chronic neurotrophic treatment is gene therapy. By introducing the gene sequences of neurotrophic factors to the cellular nucleus, the transfected cells may provide a sustainable endogenous production of neuroprotective substances. ${ }^{10,11}$ Via viral gene transfer, these factors were already implemented in the inner ear, although an expression of the introduced sequences did not demonstrate cell-specific gene transfer. ${ }^{12,13}$ Furthermore, only a temporary expression of about 3 weeks was achieved, which is not desirable in terms of long-term therapy. ${ }^{14}$ In addition, the use of viral vectors has considerable disadvantages, such as potential infection and the ability to trigger inflammatory or immunological processes. ${ }^{15}$

In addition to the viral vectors, artificially manufactured nanoparticles offer a promising ability to transport drugs and gene sequences with the ability of cargo release over a long period of time. Today, a variety of manufactured nanoparticles, which consist of organic and inorganic parts, can be assembled. In addition to their common uses in industry, a wide range of applications in health and medicine are achievable using nanoparticles. ${ }^{16}$ The advantages of nanoparticles are the impossibility of infection and the production of biodegradable scaffolds, for which a low response of the immune system is expected. Furthermore, nanoparticles can be produced inexpensively. By considering the property of the production of biological building principles, nanoparticles are ideal for the transport of medical drugs or genes. In addition to the transport function, it is possible to modify the surface of nanoparticles with specific receptors so that they will selectively bind to specific cells. The use of nanoparticles as a targeted treatment of specific cell populations results in a significant reduction of side effects. ${ }^{16}$

Recent research proved that fluoresceine-5-isothiocyanate (FITC)-labeled lipidic nanocapsules (LNC), locally inserted into the scala tympani of guinea pigs, infiltrated cell populations of the inner ear without causing functional or anatomical damage. ${ }^{17}$ Those data were the first to demonstrate the ability of drug-unloaded LNC to enter inner ear cells. However, LNCmediated drug delivery was not examined in that study.

Besides the density of healthy SGC, the optimal effectiveness of cochlear implants is influenced by another important factor. In the postoperative onset of foreign body reaction, the organism encapsulates the implant through the production of fibrous tissue growth. This results in decreased nerveelectrode interaction, increased spread of neuronal excitation, reduced frequency selectivity, and increased impedances. ${ }^{18}$

Rolipram, an intracellular-acting phosphodiesterase-4 inhibitor, showed neuroprotective properties in former studies. ${ }^{19,20}$ Furthermore, anti-inflammatory effects have also been proven in animal models. ${ }^{21}$ We hypothesize that rolipram can potentially protect SGCs and reduce inflammatory reactions. If applied systemically, intravenously, or orally, rolipram has a bioavailability of $74 \%-77 \% .{ }^{22}$ However, due to the blood-brain barrier, systemically-applied drugs that are used for inner ear treatment must be administered in such high 
dosages to have a biological effect on their target cells in the inner ear, that side effects may occur. To avoid massive side effects, local treatment of the inner ear is favored. In order to decrease the drugs applied locally to the inner ear, a targeted drug delivery is preferable. By encapsulating rolipram into a vehicle, such as LNC, a targeted drug delivery may be realized in the future. This will decrease the amount of drugs that are needed for human therapy. In the inner ear, a targeted drug delivery will lead to a significant dosage reduction and, as a result, to a lower risk of side effects when compared to systemic treatment. Additionally, the lower dose is also economically beneficial. We hypothesize that LNC provide a feasible drug-delivery system that can be used to transport rolipram into the cytoplasm. Once in the cytoplasm, rolipram will be released and induce its biological effects.

This study examines the effect of rolipram and rolipram encapsulated in LNC on the survival rate, soma diameter, and neurite length of neonatally-harvested SGC in order to determine whether the drug's effect is increased using LNC as a drug-delivery system.

Furthermore, the effect of rolipram and the combination of LNC and rolipram is evaluated on the tumor necrosis factor- $\alpha$ (TNF- $\alpha$ ) secretion of lipopolysaccharide (LPS)stimulated dendritic cells (DC). This experiment indirectly provides information about the release of the payload and may demonstrate the potential of LNC as a delivery system for rolipram. Additionally, the results provide further insight into the anti-inflammatory effect of rolipram. This effect is due to the key role that TNF- $\alpha$ plays in the proinflammatory processes, which is appreciable in reducing postoperative reactions on cochlear implants.
Based on in vitro results, we performed experiments on systemically deafened guinea pigs in order to examine LNC's suitability for rolipram delivery in vivo.

\section{Materials and methods Lipidic nanocapsules}

In order to formulate LNC, the laboratory "Ingénierie de la Vectorisation Particulaire", University of Angers (Angers, France) used a novel phase inversion-based method. ${ }^{23}$ The nanoparticles, which consisted of a liquid core, were surrounded by a cohesive surfactant layer at the oil-aqueous interface (Figure 1A). The lipophilic Labrafac ${ }^{\circledR}$ WL 1349 (Gattefossé SA, Saint-Priest, France), which is comprised of capric and caprylic acid triglycerides, was used to obtain the oily phase of the particles, whereas the aqueous phase included $\mathrm{NaCl}$ (Prolabo, Fontenay-sous-Bois, France) that was dissolved in Milli-Q-plus ${ }^{\circledR}$ purified water (Millipore, Billerica, MA). Hence, the LNC preparation required two tensioactive surfactants: Lipoïd ${ }^{\circledR}$ S75-3 (Lipoïd GmbH, Ludwigshafen, Germany), a soybean lecithin made of phosphatidylcholine (69\%), phosphatidylethanolamine (10\%), and other phospholipids, and Solutol ${ }^{\circledR}$ HS 15 (BASF, Ludwigshafen, Germany), a composition of free polyethylene glycol (PEG) 660 and PEG 660-hydroxystearate. In order to prepare LNC with a mean diameter of $50 \mathrm{~nm}$, the compounds were used in the following amounts: $1.028 \mathrm{~g}$ Labrafac $^{\circledR}, 0.075 \mathrm{~g} \mathrm{Lipoïd}^{\circledR}, 0.846 \mathrm{~g} \mathrm{Solutol}^{\circledR}, 0.089 \mathrm{~g}$ $\mathrm{NaCl}$, and $2.962 \mathrm{~g}$ pure water. Magnetic stirring (200 rpm) at room temperature resulted in an oil-in-water emulsion of all compounds. A progressive heating rate of $4^{\circ} \mathrm{C} /$ minute obtained the inverted phase (water-in-oil) at a temperature
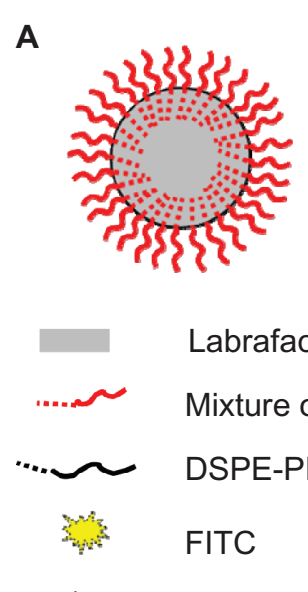

Labrafac $^{\circledR}$

Mixture of Lipoïd ${ }^{\circledR}$ and Solutol ${ }^{\circledR}$

DSPE-PEG2000-amino

FITC

Rolipram
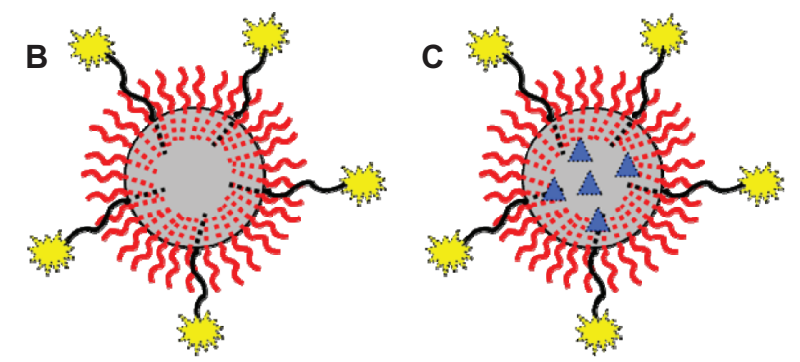

Figure I (A) Lipidic nanocapsule; (B) lipidic nanocapsule labeled with FITC, and (C) lipidic nanocapsule with rolipram encapsulation and FITC label. Abbreviations: DSPE-PEG2000-amino, 1,2-distearoyl-sn-glycero-3-phosphoethanolamine-N-[amino(PEG)2000]; FITC, fluorescein isothiocyanate. 
of $85^{\circ} \mathrm{C}$, with a phase inversion zone of approximately $70^{\circ} \mathrm{C}$. This phase inversion zone corresponded to a microemulsion state and three temperature cycles, ranging from $60^{\circ} \mathrm{C}$ to $85^{\circ} \mathrm{C}$, were performed to ensure a stable oil-in-water emulsion. The LNC formulation was accomplished using a fast cooling-dilution process during the phase inversion zone, with $12.5 \mathrm{~mL}$ cold water in a ratio of $1: 2.5$. The LNC that were obtained had a diameter of $50 \mathrm{~nm}$. For this purpose, the dilution was stirred for 5 minutes at $2^{\circ} \mathrm{C}$.

To encapsulate rolipram (Sigma-Aldrich, Lyon, France), the drug was added before starting the three temperature cycles at a concentration of $1 \mathrm{mg} / \mathrm{mL}$ in Labrafac ${ }^{\circledR}$.

The LNC surface was modified using a 1,2-distearoylsn-glycero-3-phosphoethanolamine-N-[amino(PEG)2000] (DSPE-PEG2000-amino) post-insertion process. $1.75 \mathrm{~mL}$ LNC $\left(10^{17}\right.$ particles $\left./ \mathrm{mL}\right)$ were incubated with a $1.25 \mathrm{~mL}$ aqueous micellar solution (15 mg/mL) of DSPE-PEG2000amino (Avanti ${ }^{\circledR}$; Polar Lipids Inc, Alabaster, AL) for 90 minutes at $60^{\circ} \mathrm{C} .{ }^{24}$ The obtained suspension was vortexed every 15 minutes and quenched in ice water for 60 seconds.

FITC-labeling of the LNC was performed with FITC (Figure 1B) purchased from Sigma-Aldrich. $1 \mathrm{~mL}$ of FITC ( $2 \mathrm{mg} / \mathrm{mL}$ ) was added to the $2.95 \mathrm{~mL} \mathrm{LNC} \mathrm{suspension.} \mathrm{By}$ adding an appropriate amount of $0.1 \mathrm{M} \mathrm{Na}_{3} \mathrm{PO}_{4}$, the $\mathrm{pH}$ was increased to 9 . The sample, which was placed in a water bath and protected from light, was stirred at a temperature of $37^{\circ} \mathrm{C}$ for 45 minutes before being cooled down in an ice bath for 3 minutes to stop the process.

In order to separate the free FITC from the labeled LNC size, exclusion chromatography on a Sephadex G-25 column (Pharmacia, Uppsala, Sweden) was executed. Fluorescence spectroscopy (FITC detection), as well as turbidity at $680 \mathrm{~nm}$ (LNC detection), was measured for each fraction. Integrity control of the LNC was performed by size measuring using a dynamic light scattering (DLS) procedure on the fractions that contained the particles.

DLS analysis and electrokinetic measurements indicated a hydrodynamic diameter of $52 \pm 5 \mathrm{~nm}$ and a $\zeta$-potential of $-50 \pm 10 \mathrm{mV}$. Finally, the concentration of the LNC solution was $4 \times 10^{15}$ particles $/ \mathrm{mL}$.

For rolipram loading in the $\mathrm{LNC}$, as well as for the modification by FITC (Figure 1C), the purification step was modified. After the grafting step, the mixture was dialyzed (MWCO $15 \mathrm{kDa}$ ) against pure water over night and the concentration was adjusted so as to obtain $4 \times 10^{15}$ particles $/ \mathrm{mL}$. Hydrodynamic diameter and $\zeta$-potential were checked and were found to be comparable with those obtained by LNC without rolipram.

\section{In vitro experiments}

\section{Spiral ganglion cell culture}

The dissociation of SGC from 3-5-day-old Sprague-Dawley rats was performed in accordance with the German law on protecting animals $(\$ 4 / 03)$. Before cell preparation, 96-multiwell culture plates (Nunc GmbH, Wiesbaden, Germany) were sequentially coated with polyornithine (Sigma, St, Louis, MO) and laminin (Invitrogen, Karlsruhe, Germany). ${ }^{25}$ A total number of $1.5 \times 10^{4}$ cells were seeded per well in $100 \mu \mathrm{L}$ of modified panserin-based media. Panserin $(15 \mathrm{~mL})$ was supplemented with $375 \mu \mathrm{L} 1 \mathrm{M}$ HEPES (Sigma, Steinheim, Germany), $275 \mu \mathrm{L}$ phosphate-buffered saline (PBS; Invitrogen), $225 \mu \mathrm{L}$ penicillin (Grünenthal, Aachen, Germany), $82.5 \mu \mathrm{L}$ glucose (30\% in PBS), $35 \mu \mathrm{L}$ insulin (Invit-

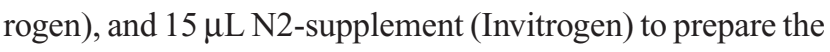
media. The following experimental groups were performed in different concentrations: LNC labeled with FITC (LNCFITC), rolipram (rolipram; TOCRIS Bioscience, Ellisville, $\mathrm{MO}$ ), and LNC-FITC with rolipram (LNC-FITC-rolipram). BDNF (50 ng/mL; R\&D Systems, Wiesbaden, Germany) was used as a positive control.

Rolipram was used in concentrations of $38 \mathrm{ng}$ (1:50 dilution, $\mathrm{n}=20), 19 \mathrm{ng}(1: 100$ dilution, $\mathrm{n}=20), 9.5 \mathrm{ng}$ ( $1: 200$ dilution, $\mathrm{n}=20)$, and $6.3 \mathrm{ng}(1: 300$ dilution, $\mathrm{n}=20)$ per $0.1 \mathrm{~mL}$ medium. The stock solution of LNC contained $45 \mathrm{mg} / \mathrm{mL}\left(4.2 \times 10^{15} \mathrm{LNC} / \mathrm{mL}\right)$ FITC-labeled LNC and $19 \mu \mathrm{g} / \mathrm{mL}$ rolipram, respectively. The used dilutions contained $0.9 \mathrm{mg} / \mathrm{mL}$ LNC (1:50 dilution), $0.45 \mathrm{mg} / \mathrm{mL}$ LNC (1:100 dilution), $0.225 \mathrm{mg} / \mathrm{mL}$ LNC (1:200 dilution), and $0.15 \mathrm{mg} / \mathrm{mL}$ LNC (1:300 dilution).

After 48 hours cultivation time at $37^{\circ} \mathrm{C}$ and $5 \% \mathrm{CO}_{2}$, cells were fixed with 1:1 methanol/acetone. Immunochemical staining with 200-kD neurofilament antibodies (Vectastain ABC Kit ELITE Mouse IgG; Vector Laboratories, Burlingame, CA) enabled a clear identification of SGC. Untreated SGC, cultured with supplemented panserin only, served as a negative control. In order to determine the absolute number of seeded SGC, the seeding control was fixed after 4 hours. The mean of positive $200-\mathrm{kD}$-stained cells of the seeding control was set as $100 \%$.

Vital SGC were defined as positive-stained neurons that showed a neurite outgrowth of at least three soma diameters. From five different fields of view within each well, one neuron was selected for the purpose of measuring the length 
of the neuron and the neurite as described previously. ${ }^{26}$ Cell survival rate was determined by the number of vital neurons in correlation to the seeding control data.

\section{SGC culture: investigation of LNC-FITC neuroprotective effect}

The first SGC in vitro test revealed the neuroprotective potential of the LNC-FITC nanoparticles (Figure 3A), even though they were not loaded with the payload rolipram. A second test was performed to verify whether the nanoparticle itself or the fluorescein FITC had a positive effect on the SGC survival of the drug-unloaded LNC-FITC particles.

LNC-FITC nanoparticles were added to the SGC culture as described above in three different concentrations (1:100, 1:200, 1:300 dilution of stock solution of $45 \mathrm{mg} / \mathrm{mL} \mathrm{LNC)}$. LNC Blank particles (LNC without FITC labeling) were added in an analogous procedure. Furthermore, BDNF $50 \mathrm{ng} / \mathrm{mL}$-treated cells were used as a positive control. The cell culture medium of the seeding and the negative control remained untreated.

SGC were seeded in a mean density of $1.5 \times 10^{4}(247.3 \pm$ $59.8 \mathrm{SGC}$ in seeding control [mean \pm standard deviation]; $\mathrm{n}=6$ ). In three independently performed experimental settings (plates), each group included three wells per setting.

\section{Dendritic cell culture}

DCs were generated from femoral BALB/c mice (Charles River, Sulzfeld, Germany) bone marrow, according to an approved protocol ${ }^{27}$ and in accordance with the German law on protecting animals $(\S 4 / 03)$. The bone marrow was flushed with $5 \mathrm{~mL} 4^{\circ} \mathrm{C}$ PBS out of the femur and centrifuged for 10 minutes at $290 \mathrm{~g}$ at $4^{\circ} \mathrm{C}$. The supernatant was discarded to resuspend the cell pellet with RPMI 1640 (Biochrom, Berlin, Germany), which was supplemented with $10 \%$ fetal calf serum (FCS) and $50 \mu \mathrm{mol} / \mathrm{L} 2$-mercaptoethanol (Sigma, Deisenhofen, Germany). A total amount of $2.5 \times 10^{6}$ cells was added to $10 \mathrm{~mL}$ supplemented RPMI in a petri dish (Cell+; Sarstedt, Nümbrecht, Germany). Before cultivation at $37^{\circ} \mathrm{C}$ and $5 \%$ $\mathrm{CO}_{2}, 20 \mathrm{ng} / \mathrm{mL}$ granulocyte-macrophage colony-stimulating factor (GM-CSF; R\&D System, Minneapolis, MN) was added. On day 3,10 mL of fresh medium containing $20 \mathrm{ng} / \mathrm{mL}$ GMCSF was added. On day 6 and $8,10 \mathrm{~mL}$ of the culture media was removed and centrifuged to harvest the included cells. The cell pellet was resuspended in $10 \mathrm{~mL}$ of fresh media, which was supplemented with $20 \mathrm{ng} / \mathrm{mL}$ GM-CSF. On day 10, a number of $5 \times 10^{4}$ cells were seeded in $200 \mu \mathrm{L}$ RPMI-media per well on a 96-multiwell plate. Rolipram (Tocris Bioscience),
LNC-FITC-rolipram, LNC-FITC, and LNC-Blank were added in four concentrations $(10 \mu \mathrm{M}, \mathrm{n}=12 ; 1 \mu \mathrm{M}, \mathrm{n}=12$; $0.1 \mu \mathrm{M}, \mathrm{n}=12 ; 0.01 \mu \mathrm{M}, \mathrm{n}=12$ ). One hour after incubation with the test substances, DCs were stimulated with LPS to induce TNF- $\alpha$ production. After 24 hours, the supernatant was collected and the TNF- $\alpha$ concentration was measured using ELISA (R\&D Systems, Minneapolis, MN).

\section{In vivo study}

\section{Experimental animals}

Female nonpigmented Dunkin Hartley guinea pigs (Charles River GmbH, Sulzfeld, Germany), weighing between 330 $460 \mathrm{~g}$, were used. After confirmation of physiological hearing via acoustically evoked auditory brainstem response (AABR) measurement on day 0 , the animals were systemically deafened. On day 7, in order to confirm deafness, AABR measurement was repeated and animals were treated with LNC-FITC $(n=7)$, LNC-FITC-rolipram $(n=6)$, rolipram $(n=7)$, or PBS $(n=6$; control group) via unilateral cochleostomy. Contralateral PBS was applied as a control. After 3 weeks of deafness, animals were sacrificed for tissue harvesting.

The guinea pigs' care and all experiments were carried out in accordance with the German law on protecting animals and were permitted by the regional government (LAVES, registration number 07/1266).

\section{Anesthesia}

Guinea pigs were anesthetized using medetomidine $\left(0.3 \mathrm{mg} / \mathrm{kg}\right.$, Domitor ${ }^{\circledR}$; Pfizer, Berlin, Germany) and ketamine (40 mg/kg, Ketamin ${ }^{\circledR}$; WDT, Garbsen, Germany) for electrophysiological measurements and surgery. If necessary, animals received an additional injection of half of the original dosage for surgery. On experimental day 21, after final AABR measurement, all animals received a second injection of the full dosage of anesthetics 15 minutes before sacrifice as described above. One hour before surgery, $0.05 \mathrm{mg} /$ $\mathrm{kg}$ atropine sulfate (B Braun Melsungen AG, Melsungen, Germany) and $5 \mathrm{mg} / \mathrm{kg}$ carprofen (Rimadyl ${ }^{\circledR}$; Pfizer $\mathrm{GmbH}$, Karlsruhe, Germany) were applied. Before surgery in the postauricular area and before perfusion in the region to be incised, local anesthesia was performed with prilocaine (Xylonest $^{\circledR}$; AstraZeneca GmbH, Wedel, Germany).

\section{Acoustically evoked auditory brainstem response measurement}

AABR measurements were performed on day 0 to confirm the physiological hearing threshold of the animals. 
Hearing thresholds of $\leq 80 \mathrm{~dB}$ SPL at $1 \mathrm{kHz}, \leq 70 \mathrm{~dB}$ SPL at $4 \mathrm{kHz}, \leq 50 \mathrm{~dB}$ SPL, and $\leq 60 \mathrm{~dB}$ SPL at the middle frequencies $8 \mathrm{kHz}$ and $16 \mathrm{kHz}, \leq 70 \mathrm{~dB}$ SPL at $32 \mathrm{kHz}$, and $\leq 80 \mathrm{~dB}$ SPL at $40 \mathrm{kHz}$ were set as thresholds for normal hearing. On day 7, AABR was measured again to verify the efficacy of the deafening procedure. A threshold shift of $\geq 50 \mathrm{~dB}$ or above $90 \mathrm{~dB}$ SPL was determined as deaf. ${ }^{28}$ On experimental day 21 , a final measurement was carried out just before sacrifice. All AABR measurements were performed with a system (Tucker Davis Technologies, Alachua, FL) that consisted of two RX6 multifunction processors, a loudspeaker driver unit (ED1), and two electrostatic speakers (EC1). The anesthetized animals were placed on a heating pad in a soundproof box where they were exposed to acoustic stimuli by electrostatic speakers (EC1) via modified ear tips. To record the neurological responses, four needle electrodes were subdermally implanted as follows: the reference electrode was attached to the nose, the auditory evoked potentials were derived via two electrodes relative to the left and right mastoid, and the ground electrode was placed on the neck to suppress interfering signals caused by heart rate or muscle tension. The recording electrodes were broadcasting the potentials of the low-impedance converter (RA4LI) to a preamplifier (RA4PA), which transferred a digitalized signal to the multifunction processor (RX6). Measurements were controlled by BioSigRP software (Tucker Davis Technologies). The dynamic range of the stimuli (10 ms sinusoidal pulses; $1 \mathrm{~ms}$ cosine-in and fade-out-function) was settled in $10 \mathrm{~dB}$ steps from 20-90 dB SPL, whereas frequencies of $1 \mathrm{kHz}$, $4 \mathrm{kHz}, 8 \mathrm{kHz}, 16 \mathrm{kHz}, 32 \mathrm{kHz}$, and $40 \mathrm{kHz}$ were presented. In order to suppress background noise, bandpass filters were settled from $300 \mathrm{~Hz}$ to $3 \mathrm{kHz}$ at $3 \mathrm{~dB}$. In order to suppress other artifacts, a threshold of $70 \mu \mathrm{V}$ was chosen. For graphical representation, each stimulus was repeated 270 runs and averaged. The hearing threshold was determined by visual analysis as soon as a significant local maximum was observed in the course of the averaged wave. ${ }^{29}$

\section{Deafening procedure}

All animals were systemically deafened on day 0 using a common ototoxic procedure as described by Versnel and colleagues. ${ }^{30}$ After the preliminary AABR measurement, $400 \mathrm{mg} / \mathrm{kg}$ kanamycine were injected subcutaneously. In the next two hours, the jugular vein was exposed under incision of the overlaying musculature in order to inject the loop diuretic furosemide $(100 \mathrm{mg} / \mathrm{kg})$. The coadministration of the aminoglycoside kanamycine with loop diuretics results in a complete loss of sensory cells, which initiates the degeneration of SGC. Before tissue harvesting, deafness was confirmed on day 7 and 21 by AABR measurement.

\section{Application of the test substances}

On day 7 of the experiments, animals were placed in ventral alignment on a heating pad after AABR measurement was performed in order to confirm the deafness of the animals. A postauricular incision was made under aseptic conditions. The overlying muscles were removed in order to examine the Bulla tympani, which was opened in the following step. Using a microscope (Carl Zeiss AG, Oberkochen, Germany), the cochlea was visualized in the opened middle ear cavity. A small hole was drilled under the use of a lancet in the basal turn of the cochlea and the scala tympani was opened. An injection catheter was assembled using a $27 \mathrm{G}$ cannula (B Braun Melsungen AG) connected with a silicon tube (inner diameter $0.3 \mathrm{~mm}$; LiquidScan $\mathrm{GmbH}$ and $\mathrm{Co}, \mathrm{KG}$, Überlingen, Germany) and an inserted polyimide tube (inner diameter $0.12 \mathrm{~mm}$; Micro Lumen Inc, Tampa, FL) at the top. In order to avoid deep penetrations of the cochlea, a $2 \mathrm{~mm}$ sphere of carboxylate cement (ESPE Dental AG, Seefeld, Germany) was formed on the tip. The catheter was then inserted into the scala tympani to deliver a total volume of $5 \mu \mathrm{L}$ of the test substances over a period of 5 to 10 minutes into the inner ear using a $10 \mu \mathrm{L}$ Hamilton syringe (Hamilton Bonaduz AG, Bonaduz, Switzerland). The left ears were treated with the test substances (LNC-FITC $[\mathrm{n}=7]$, rolipram $[\mathrm{n}=6]$, LNC-FITC-rolipram $[\mathrm{n}=7]$, and PBS $[\mathrm{n}=6]$ ) in a dilution of 1:100. As a control, the right ears were treated with PBS. Subsequently, the cochlea and the bulla tympani were sealed with carboxylate cement (Durelon ${ }^{\circledR}$; ESPE Dental AG) and the soft tissue trauma was sutured in two layers.

\section{Histological analysis}

Anesthetized animals were sacrificed after final AABR measurement on day 21 via transcardial perfusion by $200 \mathrm{~mL}$ PBS followed by $200 \mathrm{~mL}$ of paraformaldehyde (PFA; 4\%; Merck, Darmstadt, Germany) infused in the left heart chamber. Cochleae were harvested and opened carefully at the apex and round window to exchange resisting perilymph for a fixative by slowly rinsing with $1 \mathrm{~mL}$ PFA (4\%). Samples were placed in PFA for 2 hours for further fixation. Before decalcification, the cochleae were rinsed with PBS three times. Afterwards, they were placed in 20\% EDTA (SigmaAldrich Chemie GmbH, Steinheim, Germany) for 4-5 weeks at $37^{\circ} \mathrm{C}$. Decalcification media was changed every 2 or 3 days. Before paraffin embedding, dehydration with 
50\%-100\% ethanol (BÜFA Chemikalien, Altmoorhausen, Germany) was performed. $5 \mu \mathrm{m}$ midmodiolar sections were generated from paraffin blocks, mounted on glass slides and stained with hematoxylin and eosin.

For analysis, all cochlea turns were identified with an Axiovert 25C Microscope (Carl Zeiss AG). The turns were named lower basal turn (lb), upper basal turn (ub), first middle turn $(1 \mathrm{~m})$, second middle turn $(2 \mathrm{~m})$, third middle turn $(3 \mathrm{~m})$, fourth middle turn (4 m), and apical turn (a) (Figure 2). Due to preparation methods, the $4 \mathrm{~m}$ and a turn could not always be analyzed separately. Therefore, the SGC densities of these areas, if available, were added for analysis. The first midmodiolar section was selected randomly. Every fifth following section was chosen for analysis to ensure a separation of $25 \mu \mathrm{m}$ between the sections. In total, five sections per cochlea were analyzed.
Next to the perikaryal diameter, the number of surviving SGC with a visible nucleus was examined. The number of surviving SGC in correlation to the measured cross-sectional area of the Rosenthal's canal provides the SGC density, which can be expressed as cells $/ 10.000 \mu \mathrm{m}^{2}$. Soma diameter measurement was performed by dividing the area of each Rosenthal's canal in four equal parts. In each part, two representative SGC were chosen for measurement. In case of less than eight surviving SGC, every visible cell was measured.

\section{Statistical analysis}

All data passed the normality test (Kolmogorov-Smirnov). Student-Newman-Keuls analysis of variance (ANOVA) was performed for in vitro data analysis. In vivo data were first analyzed using a paired $t$-test to compare the treated and

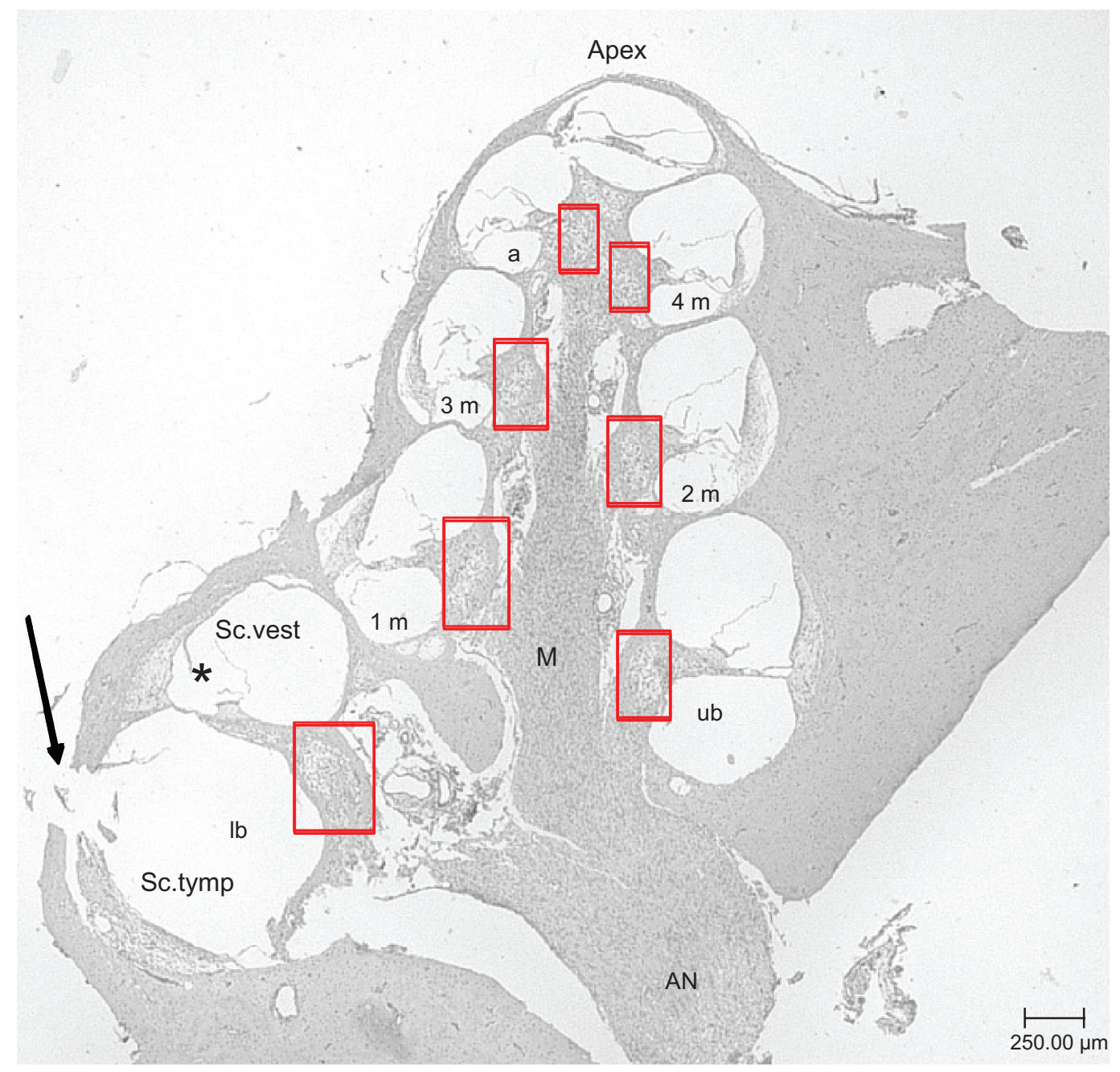

Figure 2 Representative midmodiolar hematoxylin and eosin-stained section $(5 \mu \mathrm{m})$ of a deafened guinea pig cochlea. Rosenthal's canal areas are highlighted in red squares. Lower basal turn (lb), upper basal turn (ub), first middle turn ( $\mathrm{l} \mathrm{m})$, second middle turn $(2 \mathrm{~m})$, third middle turn ( $3 \mathrm{~m})$, fourth middle turn (4 m), and apical turn (a) of the scala tympani are labeled. The arrow marks the cochleostomy where the solutions were injected into the scala tympani. The modiolus, the axis of the inner ear, and the apex, the upper part of the inner ears are marked.

Note: *scala media.

Abbreviations: AN, auditory nerve; M, modiolus; Sc. tymp, scala tympani; Sc. vest, scala vestibuli (magnification: 40-fold). 
untreated ears of one animal group. Comparisons between the treated (left) ears of all groups, as well as the comparisons with the untreated (right) ears were performed using Student-Newman-Keuls ANOVA.

\section{Results}

\section{SGC in vitro study - neuronal survival}

SGC were seeded in a mean density of $1.5 \times 10^{4}$ cells $/$ well. The seeding control was evaluated after 4 hours of cultivation and contained $229.6 \pm 18.1$ (mean \pm standard deviation [SD]; $\mathrm{n}=12)$ SGC. This was set as the reference value $(100 \%)$ for the experimental groups that were fixated after 48 hours. In five independently performed experimental settings (independent plates on different days), each group included 4-8 wells. Thus, each concentration of the test substances (1:50, 1:100, $1: 200,1: 300$ ) was tested in a minimum of 20 wells. For BDNF treatment, 30 wells were used as positive control; for the untreated negative control, 12 wells were examined. Figure 3A depicts the mean and SD percentage of surviving SGC for each experimental group.

BDNF had the best results with a highly significant increased neuron survival in comparison to the negative control $(45.7 \% \pm 12.6 \%$ versus $10.7 \% \pm 4.2 \% ; P<0.001)$, as well as compared to all other experimental groups $(P<0.001)$. Pure rolipram did not enhance neuronal survival. Homogenous values of $15.7 \% \pm 4.5 \%$ survival rate in mean for each dilution of rolipram induced no significant difference when compared to the negative control, although a tendency toward an increased survival rate was visible. In combination with LNC, rolipram increased the neuronal survival in the $1: 100(32.6 \% \pm 9.7 \%$; $P<0.001)$ dilution. In comparison to the negative control, the $1: 200(23.4 \% \pm 7.2 \% ; P<0.01)$ and $1: 300$ dilution $(20.0 \% \pm 6.4 \% ; P<0.05)$ proved to be neuroprotective as well. The $1: 50(16.2 \% \pm 10.2 \%)$ dilution could not induce any benefits.

Treatment with unloaded LNC (FITC-labeled, but not containing rolipram) resulted in increased neuronal survival as well, though the effect was weaker than in the LNC-FITC-rolipram group. In this group, the 1:100 $(24.4 \% \pm 8.8 \% ; P<0.001)$ and the $1: 200(20.7 \% \pm 7.6 \%$; $P<0.01)$ dilution showed positive effects.

Because LNC-FITC nanoparticle treatment resulted in increased neuronal survival, an additional test was performed to evaluate which nanoparticle component - the nanoparticle itself or the fluorescein FITC - has neuroprotective properties. The results revealed neuroprotective effects of the particle itself. As shown in Figure 4, LNC-Blank particles significantly increased the survival rate in comparison to the negative control.

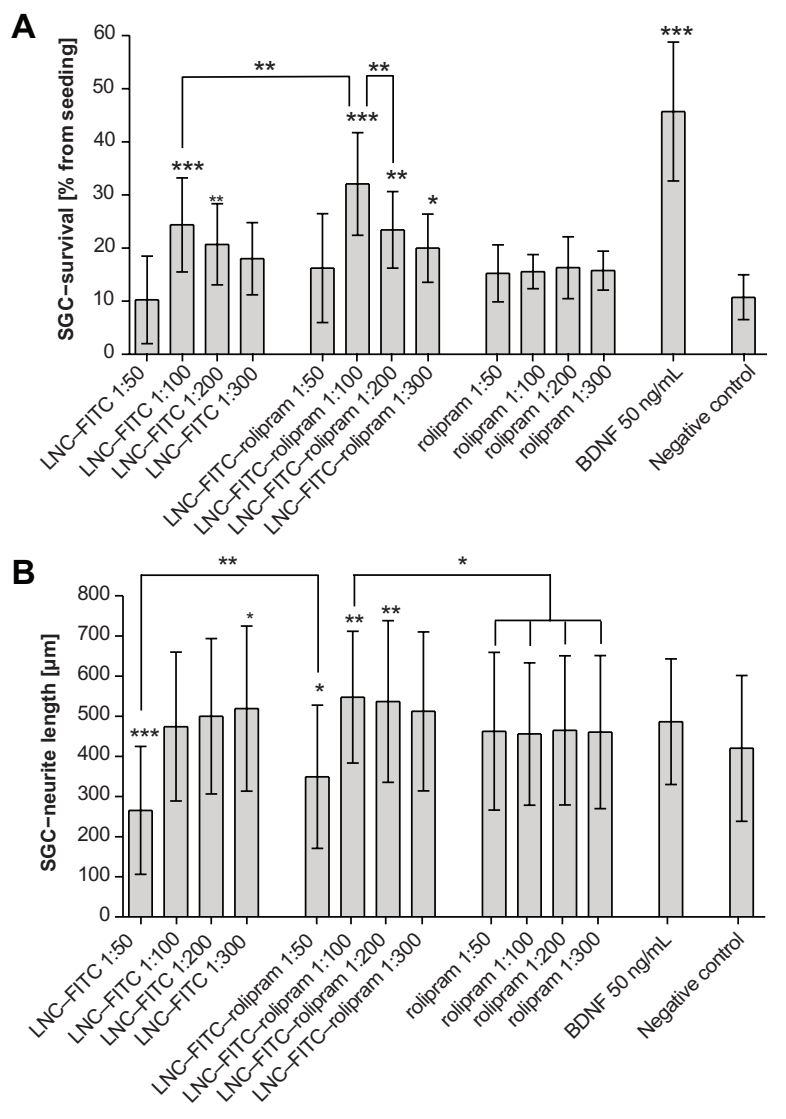

Figure 3 (A) Survival rates of cultured SGC treated with LNC-FITC, LNC-FITCrolipram, rolipram, and BDNF in different concentrations. Rolipram was used in concentrations of $38 \mathrm{ng}$ ( $1: 50$ dilution; $\mathrm{n}=5$; total: 20 wells), $19 \mathrm{ng}$ ( $1: 100$ dilution; $\mathrm{n}=5$; total: 20 wells), $9.5 \mathrm{ng}$ ( $1: 200$ dilution; $\mathrm{n}=5$; total: 20 wells), and $6.3 \mathrm{ng}$ ( $1: 300$ dilution; $\mathrm{n}=5$; total: 20 wells) per $0.1 \mathrm{~mL}$ medium. Stock solution of LNC contained $45 \mathrm{mg} / \mathrm{mL}$ FITC $\left(4.2 \times 10^{15} \mathrm{LNC} / \mathrm{mL}\right)$. LNC-FITC-rolipram particles contained $19 \mu \mathrm{g} / \mathrm{mL}$ rolipram. BDNF (50 ng/mL, $\mathrm{n}=5$; total: 30 wells) served as positive control. (B) Neurite outgrowth of cultured SGC treated with LNC-FITC, LNC-FITCrolipram, rolipram, and BDNF in different concentrations (mean \pm SD). LNC-FITC I:50 decreased the SGC-neurite length highly significantly $(P<0.00 \mathrm{I})$ compared to all other experimental groups (not marked in the graph) except the LNC-FITCrolipram I:50 group ( $P<0.0$ I; left upper line). Significant differences among treatment groups compared to the negative control are marked above the columns. Notes: $* P<0.05$; ** $P<0.01$; *** $P<0.001$.

Abbreviations: BDNF, brain-derived neurotrophic factor; FITC, fluorescein isothiocyanate; LNC, lipidic nanocapsules; SD, standard deviation; SGC, spiral ganglion cells.

\section{SGC in vitro study: neurite lengths}

Neurite lengths of the negative control were measured with a mean of $420.1 \pm 181.5 \mu \mathrm{m}$ (mean $\pm \mathrm{SD}$ ). BDNF and rolipram did not influence the neurite outgrowth, whereas the 1:50 dilutions of the LNC-FITC $(265.6 \pm 159.4 \mu \mathrm{m} ; P<0.001)$ and LNC-FITC-rolipram group $(349.3 \pm 178.3 \mu \mathrm{m}$; $P<0.05)$ induced significantly decreased neurite lengths. In comparison to the negative control, LNC-FITC showed a positive effect on the neurite lengths in the 1:300 dilution $(519.1 \pm 205.4 \mu \mathrm{m} ; P<0.05)$, LNC-FITC-rolipram in the 1:100 (547.6 $\pm 164.1 \mu \mathrm{m} ; P<0.01)$, and 1:200 dilution (536.8 $\pm 201.1 \mu \mathrm{m} ; P<0.01)$, whereas the other dilutions did not differ from the negative control (Figure 3B). 


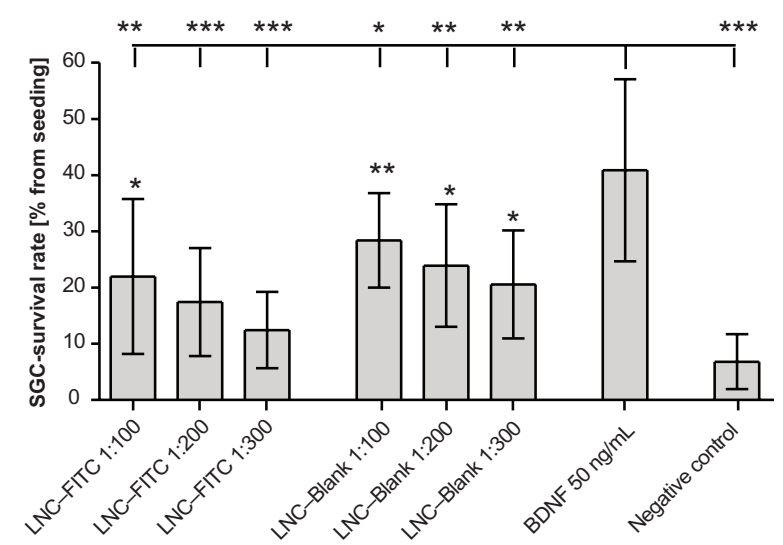

Figure 4 Survival rates of cultured SGC treated with LNC-FITC and LNC-Blank in different concentrations ( $n=9$ for each group, mean $\pm S D$ ). Stock solution of LNC contained $45 \mathrm{mg} / \mathrm{mL}$ FITC $\left(4.2 \times 10^{15} \mathrm{LNC} / \mathrm{mL}\right)$. BDNF $(50 \mathrm{ng} / \mathrm{mL}, \mathrm{n}=9)$ served as positive control. The SGC survival rate of all experimental groups differed significantly from the survival rates of neurons treated with BDNF (upper horizontal line; $* P<0.05 ; * * P<0.01$; $* * * P<0.001$ ). Statistically significant differences of LNC (with and without FITC)-treated SGC compared to the negative control are marked above the respective column.

Abbreviations: BDNF, brain-derived neurotrophic factor; FITC, fluorescein isothiocyanate; LNC, lipidic nanocapsules; SD, standard deviation; SGC, spiral ganglion cells.

\section{SGC in vitro study: soma diameter}

The mean soma diameter of the negative control was $14.5 \pm 2.6 \mu \mathrm{m}($ mean $\pm \mathrm{SD}, \mathrm{n}=60)$. Only the cell diameter of the 1:50 LNC-FITC (stock solution: $45 \mathrm{mg} / \mathrm{mL} \mathrm{LNC)-}$ treated SGC showed a significant decrease in soma diameter $(12.8 \pm 1.9 \mu \mathrm{m} ; P<0.01)$. None of the other groups provided statistically significant differences when compared with the

Table I Results of the measured soma diameter of SGC (mean $\pm \mathrm{SD}$ ) after 48 hours cultivation with LNC-FITC, LNCFITC-rolipram, rolipram, or BDNF in the shown concentrations

\begin{tabular}{llll}
\hline Experimental group & $\begin{array}{l}\text { Mean soma } \\
\text { diameter } \\
{[\mu \mathrm{m}]}\end{array}$ & SD & $\begin{array}{l}\text { Number of } \\
\text { measured } \\
\text { somae }\end{array}$ \\
\hline Negative control & 14.5 & 2.6 & 60 \\
LNC-FITC I:50 & 12.8 & 1.9 & 100 \\
LNC-FITC I:I00 & 13.2 & 2.2 & 100 \\
LNC-FITC I:200 & 13.3 & 2.2 & 100 \\
LNC-FITC I:300 & 14.0 & 3.2 & 100 \\
LNC-FITC-rolipram I:50 & 13.3 & 2.1 & 100 \\
LNC-FITC-rolipram I:I00 & 14.0 & 2.6 & 100 \\
LNC-FITC-rolipram I:200 & 13.7 & 2.8 & 100 \\
LNC-FITC-rolipram I:300 & 14.1 & 3.0 & 100 \\
Rolipram I:50 & 14.4 & 2.6 & 100 \\
Rolipram I: I00 & 14.7 & 2.9 & 100 \\
Rolipram I:200 & 14.6 & 3.0 & 100 \\
Rolipram I:300 & 14.6 & 3.1 & 100 \\
BDNF 50 ng/mL & 14.8 & 2.7 & 130 \\
\hline
\end{tabular}

Abbreviations: BDNF, brain-derived neurotrophic factor; FITC, fluorescein isothiocyanate; LNC, lipidic nanocapsules; SGC, spiral ganglion cells. average cell diameter of the negative control. Values are shown in Table 1.

\section{DC in vitro study - TNF- $\alpha$ inhibition}

Per well $5 \times 10^{4}$ DCs were seeded. For each concentration and experimental group, four wells were performed per plate. Three repeated settings resulted in a total of 12 wells per concentration and group.

The TNF- $\alpha$ production of all rolipram-treated DC was significantly inhibited when compared to the positive control $(338.18 \pm 41.82 \mathrm{pg}$ TNF- $\alpha / \mathrm{mL}$; mean $\pm \mathrm{SD})$. The inhibition was dose-dependent: higher rolipram concentrations induced higher TNF- $\alpha$ suppression (Figure 5). A similar decrease was shown in the LNC-FITC-rolipram-treated group, though the values demonstrated a weaker inhibition of the TNF- $\alpha$ production. LNC-Blank nanoparticles caused a slight inhibition of the cytokine in the concentration of $1 \mu \mathrm{M}(283.11 \pm 23.01 \mathrm{pg} / \mathrm{mL} ; P<0.05)$. A strong decrease of TNF- $\alpha$ secretion was caused by LNC-Blank particles with the concentration $10 \mu \mathrm{M}(98.11 \pm 81.29 \mathrm{pg} / \mathrm{mL} ; P<0.001)$. The LNC-FITC nanoparticles showed resembling characteristics when compared to the LNC-Blank particles with a very strong inhibition in the $10 \mu \mathrm{M}$ concentration $(146.90 \pm 7.64 \mathrm{pg} / \mathrm{mL} ; P<0.001)$. By microscopic examination of the DC culture, granulation and misshaping of the cells in the $10 \mu \mathrm{M}$ nanoparticles groups (LNC-Blank, LNCFITC, LNC-FITC-rolipram) was observed. Cell vitality tests confirmed toxic effects in these concentrations (data in Supplementary materials).

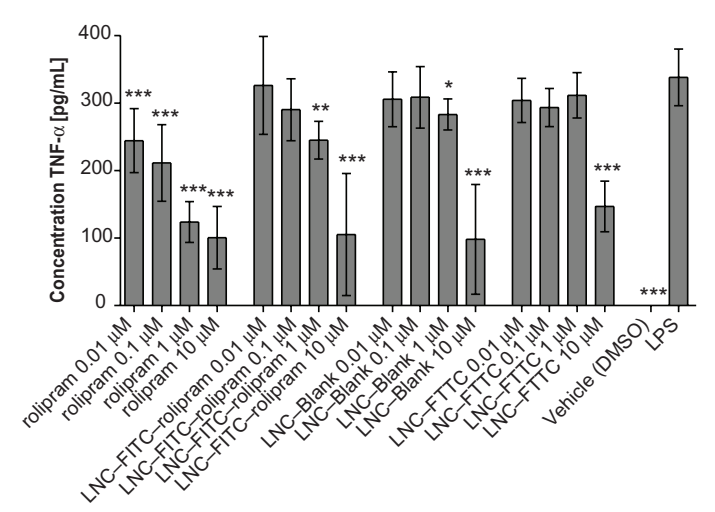

Figure 5 TNF- $\alpha$-secretion of DCs treated with rolipram, LNC-FITC-rolipram, LNC-Blank, and LNC-FITC in different concentrations. DC were stimulated with LPS I hour after incubation with the test substances. Data show mean \pm SD from three independent experiments: each consisted of $n=12$ wells per concentration per group. Statistically significant differences in TNF- $\alpha$ secretion compared to the LPS-control group are plotted above the columns.

Notes: $* P<0.05$; ** $P<0.01$; *** $P<0.001$

Abbreviations: BDNF, brain-derived neurotrophic factor; DC, dendritic cells; FITC, fluorescein isothiocyanate; LNC, lipidic nanocapsules; SD, standard deviation; SGC, spiral ganglion cells; TNF- $\alpha$, tumor necrosis factor- $\alpha$. 


\section{In vivo results}

\section{AABR measurements}

To determine the hearing threshold, animals underwent AABR measurements on day 0,7 and 21 of the study.

A preliminary AABR was performed just before the systemic deafening on day 0 to confirm the physiological hearing property of the animals. At $1 \mathrm{kHz}$, the threshold was shown at $72.90 \pm 12.43 \mathrm{~dB}$ SPL, at $4 \mathrm{kHz} 61.44 \pm 12.55 \mathrm{~dB} \mathrm{SPL}$, at $8 \mathrm{kHz} 36.14 \pm 11.62 \mathrm{~dB}$ SPL, at $16 \mathrm{kHz} 48.86 \pm 11.76 \mathrm{~dB}$ SPL, at $32 \mathrm{kHz} 49.02 \pm 9.85 \mathrm{~dB}$ SPL, and at $40 \mathrm{kHz}$ $63.91 \pm 13.61 \mathrm{~dB}$ SPL (graphed in Supplementary material). The mean difference between the left and the right ear was $5.13 \mathrm{~dB}$. The generated data showed normal hearing physiology of the tested animals according to previous studies.

The AABR measurements on day 7 and 21 were performed to confirm the deafening procedure. In no case of the measured frequencies was a positive AABR waveform visible until the measuring limit of $90 \mathrm{~dB}$ SPL. According to the literature, a threshold shift of $50 \mathrm{~dB}$ confirmed a successful deafening procedure. ${ }^{28}$

\section{SGC densities in vivo}

No significant differences concerning the SGC densities were observed when the data from the treated left ears were compared (Figure 6A). The same results occurred when the SGC densities of the right ears were compared. Furthermore, the paired $t$-test revealed no differences between the right and left ears within the test groups. Only the SGC-densities of the left and right ears of the PBS-control group varied significantly (4.14 SGC $\pm 1.40 / 10.000 \mu \mathrm{m}^{2}$; mean $\pm \mathrm{SD}$ versus 5.23 SGZ $\pm 1.67 / 10.000 \mu \mathrm{m}^{2} ; P<0.05$; Figure $6 \mathrm{~A}$ ). Representative images of Rosenthal's canal of all four treatment groups are shown in Figures 7A-D.

\section{SGC diameter in vivo}

Soma size was measured to evaluate the effect of the test substances on the cellular size. The LNC-FITC group showed a significant increase of the soma diameter between the left treated and the right control ears $(14.00 \pm 0.76 \mu \mathrm{m}$ [mean $\pm \mathrm{SD}$ ] versus $13.14 \pm 0.52 \mu \mathrm{m} ; P<0.05)$. An even more evident increase of soma diameter was observed between the left and right ear of the rolipram-treated animals $(13.78 \pm 0.26 \mu \mathrm{m}$ versus $12.73 \pm 0.32 \mu \mathrm{m} ; P<0.01)$. The SGC diameter in the LNC-FITC-rolipram group (left: $13.91 \pm 1.33 \mu \mathrm{m}$ versus right. $12.68 \pm 0.72 \mu \mathrm{m})$ and the PBS control group (left: $13.27 \pm 0.56 \mu \mathrm{m}$ versus right: $12.68 \pm 0.79 \mu \mathrm{m})$ did not differ significantly, although a difference by trend might be assumed (Figure 6B). There were

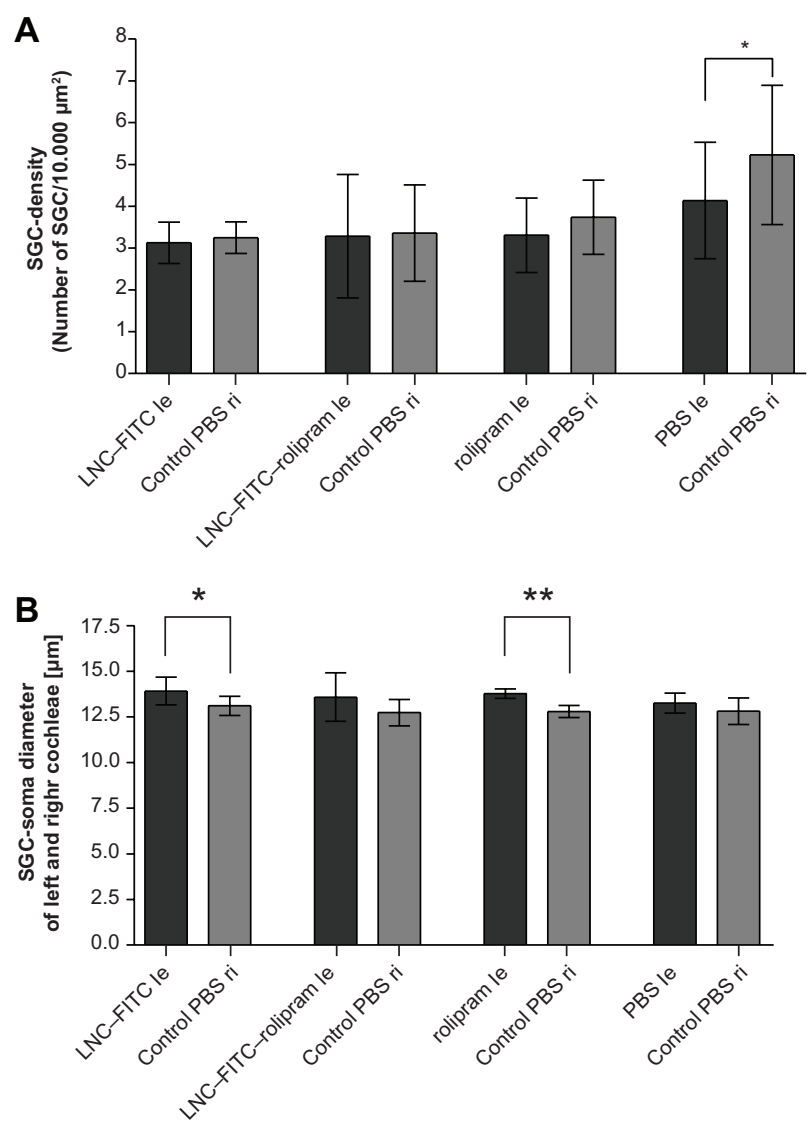

Figure 6 (A) Mean SGC density (cells/ $10.000 \mu \mathrm{m}^{2}$ ) of deafened guinea pigs treated with LNC-FITC $(n=7)$, LNC-FITC-rolipram $(n=6)$, rolipram $(n=7)$, and PBS $(\mathrm{n}=6)$ in I: 100 dilution (mean $\pm S D ; * P<0.05)$. (B) Mean SGC soma diameter of deafened guinea pigs treated with LNC-FITC, LNC-FITC-rolipram, rolipram, and PBS in I: 100 dilution (mean $\pm S D$; $* P<0.05 ; * * P<0.0$ I). Only LNC-FITC- and rolipram-treated animals showed a significant difference in SGC soma diameters between left (le, test substance) and right (ri, control).

Abbreviations: FITC, fluorescein isothiocyanate; LNC, lipidic nanocapsules; PBS, phosphate-buffered saline; SD, standard deviation; SGC, spiral ganglion cells.

no significant differences when the soma diameter of the left ears of all groups were compared. The same data unity was observed when comparing the right ears of all groups.

\section{Discussion}

This study demonstrates that BDNF $(50 \mathrm{ng} / \mathrm{mL})$ shows the most effective neuronal protection regarding the survival rate of cultured SGC. Former studies already confirmed a maximum survival rate of SGC with BDNF in this concentration. ${ }^{31}$ Due to that property, BDNF was chosen as a positive control, although the main focus was on the examination of the neuroprotective effects of rolipram and in LNC-incorporated rolipram.

Pure administration of rolipram demonstrated no efficient SGC protection in vitro in any of the used concentrations. This might be due to the intracellular mechanism of phosphodiesterase-4 inhibitors. Rolipram has to be translocated 


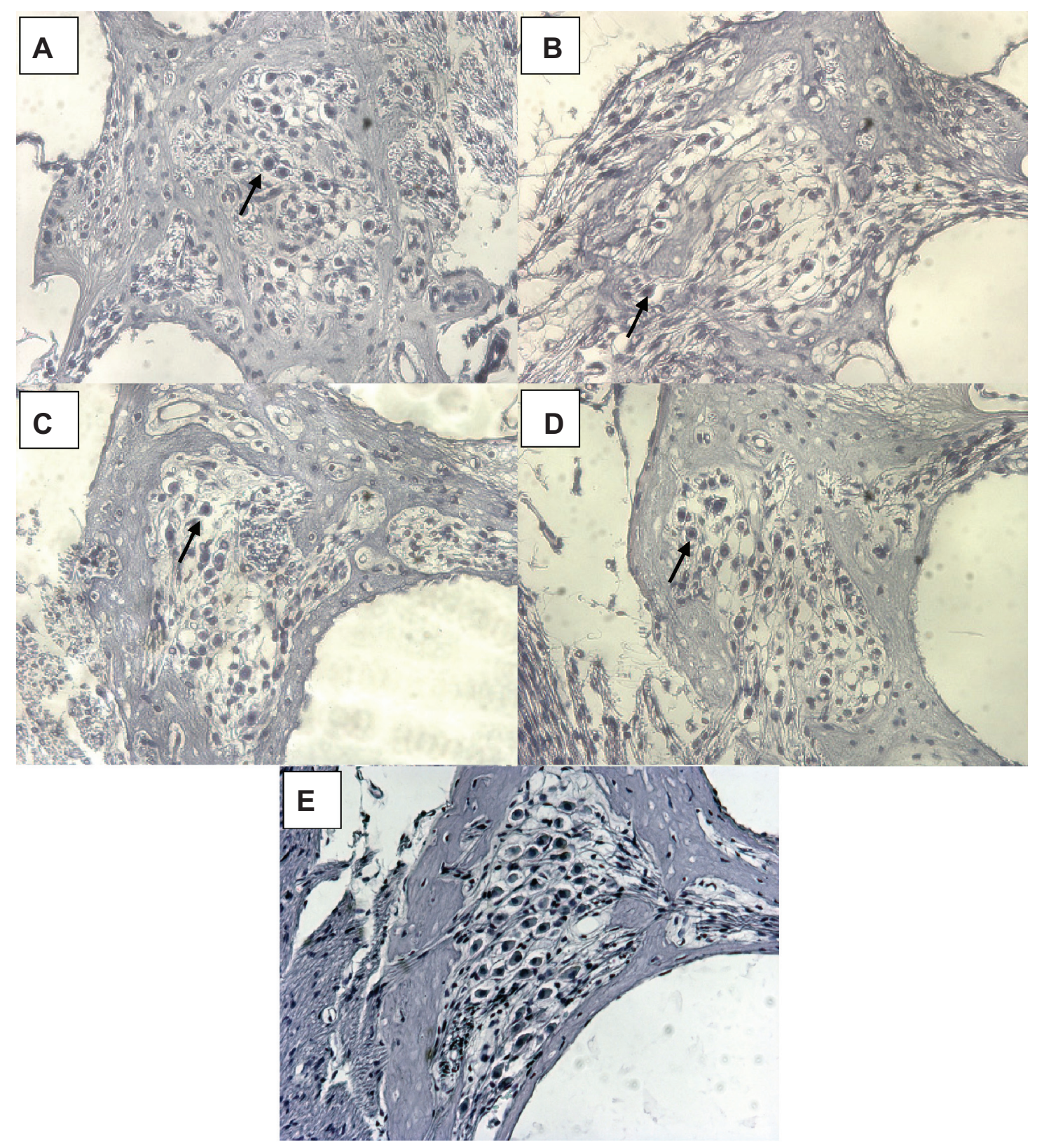

Figure 7 (A-D) Representative images of guinea pigs' Rosenthal's canals 21 days after deafening. (E) illustrates the SGC density in normal hearing animals as compared to the deafened ones in (A-D) (the picture is from a previous experiment registered at LAVES with the same registration number as the experiments described here: $07 / 1266$ ). (A) is from an animal from the LNC-FITC group receiving the nanoparticle in a I:100 dilution (stock solution $45 \mathrm{mg} / \mathrm{ml} \mathrm{LNC}$ ). (B) represents the Rosenthal's canal of animals treated with LNC-FITC-rolipram (I: 100 dilution of $45 \mathrm{mg} / \mathrm{mL} \mathrm{LNC} \mathrm{and} 19 \mu \mathrm{g} / \mathrm{mL}$ rolipram in stock solution) and (C) is from an animal that received rolipram (I:I00 dilution of $19 \mu \mathrm{g} / \mathrm{ml}$ rolipram stock solution). An image of Rosenthal's canal from the control group is shown in (D).

Notes: In each picture, an arrows point to one representative vital SGC. Magnification: 200 -fold.

Abbreviation: SGC, spiral ganglion cells.

in the cytoplasm where phosphodiesterase 4 is located. Once in the cytoplasm, rolipram inhibits phosphodiesterase 4, which leads to increased levels of cyclic adenosine monophosphate (cAMP). Proteinkinase A, which depends on cAMP, phosphorylates cAMP responsive element binding protein (CREB) in the cellular nucleus. ${ }^{32}$ The activated CREB triggers the transcription of $\mathrm{BDNF},{ }^{33}$ which leads to a neuroprotective effect. To induce this effect, the application of rolipram via LNC was chosen to enhance the intracellular concentration of rolipram, which subsequently leads to neuronal protection.

Results confirm an increased SGC survival rate using the LNC-rolipram combination. The dilution of 1:100 showed the best results in vitro, therefore this dilution was used for in vivo experiments as well. Decreasing effects of the 1:200 and 1:300 dilutions are probably caused by low concentrations, 
whereas the 1:50 dilution may have a toxic effect on cellular metabolism. Recent studies lead to the assumption that mutual reactions between the phospholipids of the particle shell and the cell membrane may cause an imbalance in endo- and exocytotic reactions. ${ }^{34}$ This consideration refers to former observations revealed in a study with polylysine nanoparticles. ${ }^{35}$ Another experiment also shows good biocompatibility of the lipid nanocapsules on fibroblast cultures. Cytotoxic effects occurred only above a concentration of $2.2 \mathrm{mg} / \mathrm{mL} .{ }^{36}$ Our own observations revealed the effects of decreased SGC survival already in the 1:50 dilution $(0.9 \mathrm{mg} /$ $\mathrm{mL}$ ), suggesting that neuronal cells are more metabolically sensitive.

The synergistic effect of rolipram and the nanoparticle is evident; the pure administration of rolipram did not significantly affect the SGC survival.

It is important to note that we found a distinct neuroprotective effect of the unloaded LNC-FITC particles as well. Compared to the LNC-FITC-rolipram combination, the SGC survival was significantly lower, which must be caused by the payload rolipram; hence the experimental groups differ only in this characteristic. To verify whether the nanoparticle itself or the fluorescein FITC are responsible for the neuroprotective effect of the drug-unloaded LNC-FITC particles, an additional SGC culture experiment was performed with FITC-unlabeled LNC. The results prove that the particle itself is responsible for the neuroprotective effects. We hypothesize that the positive effect of the unloaded particles is caused by the particle component PEG. Inserted into the particle shell, this polymer protects the drug-delivery system against the complement system of the organism to maintain a prolonged circulation time in the body. ${ }^{37,38}$ Furthermore, PEG is used for the covalent binding of FITC.

Former experiments demonstrated the neuroprotective effects of PEG in dogs suffering from intervertebral disc prolapse. ${ }^{39}$ Other studies with spinal cord injury models confirmed the beneficial effects of PEG; damaged cells were literally sealed by this polymer. ${ }^{40}$ Thus, it is remarkable that our LNC are neuroprotective themselves and are appropriate for delivering drugs, such as rolipram, to target cells in vitro to significantly increase this protective effect.

After primary hair cell loss, a progressive decrease of neurite length and SGC density is observed. ${ }^{41}$ To ensure an optimal electrical stimulation via cochlear implants, neurite preservation and, if possible, outgrowth is desired. Therefore, we measured the SGC neurite length in vitro to evaluate their outgrowth depending on the different test conditions. Rolipram did not affect the neurite outgrowth of SGC in any of the applied concentrations. Because of rolipram inhibiting phosphodiesterase 4 in the cytoplasm of cells, we hypothesize that the drug was not taken up by the neurons and therefore was not able to induce a biological effect on SGC. In contrast to this, an elongation of the neurite outgrowth was demonstrated when SGC were treated with rolipram encapsulated in LNC-FITC nanoparticles. The 1:100 and 1:200 dilutions of the LNC-FITC-rolipram particles increased the neurite outgrowth significantly. This is an indirect indication of LNC-mediated improved rolipram uptake into SGC. Next to this, cells treated with LNC-FITC 1:300 revealed a significant neurite outgrowth as well, probably due to the PEG component, as described before concerning neuronal survival. Higher concentrations (1:50 dilution) of both experimental groups induced rather short neurites, which indicates negative effects on the SGC. The rolipram-induced mechanism on neurite elongation is not clearly discovered, though a cAMP-dependent activation of protein kinase A might be involved. ${ }^{42}$ Taking this, our findings support Xu et al's report concerning the biphasic effect of the cAMP analog cpt-cAMP on neurite length. They were able to show an increased length at lower concentrations and reduced length at higher concentrations. ${ }^{43}$ On the other hand, in the present study, rolipram-loaded nanoparticles significantly elongated the neurites in 1:50 dilution when compared to the unloaded LNC in 1:50 dilution. One could speculate that this divergence is based on the rolipram and that this finding supports the hypothesis that rolipram positively affects neurite outgrowth. Until recently, limited research was available on rolipram effects and mechanisms of effects on neuronal cells. Further studies are necessary to confirm or refute the hypotheses.

Results of the perikaryal diameter showed no significant differences between the experimental groups except the SGC treated with 1:50 LNC. High concentration of LNC might induce negative effects on the cell metabolism, as described before, which influences the cell diameter.

The preincubation of DC with rolipram caused a highly significant, dose dependent inhibition of TNF- $\alpha$ secretion in all tested concentrations $(0.01 \mu \mathrm{M}, 0.1 \mu \mathrm{M}, 1 \mu \mathrm{M}, 10 \mu \mathrm{M})$ after stimulation with LPS. The collected data are in accordance with the results of a former study, ${ }^{34}$ which reported a dose-dependent reduction of LPS stimulated human DC with rolipram as well. The LNC-FITC-rolipram combination shows a similar dose-dependent decrease of TNF- $\alpha$, though the weaker effects in comparison to the pure administration might be caused by an insufficient release of the payload in the incubation time of 24 hours. Other LNC groups showed 
no or rather weak TNF- $\alpha$ inhibition in the concentrations of $0.01 \mu \mathrm{M}, 0.1 \mu \mathrm{M}$, and $1 \mu \mathrm{M}$. Upon microscopic examination, nanoparticle concentrations of $10 \mu \mathrm{M}$ caused toxic effects on the cells. Granulated and misshaped cells, as well as crystal formations, were also visible. Thus, the low concentrations of TNF- $\alpha$ in these experimental groups are caused by decreased cellular vitality and not by an TNF- $\alpha$ inhibition, which was confirmed by a cell vitality test (CellTiter $96{ }^{\circledR}$ AQueos One Solution Cell Proliferation Assay; Promega, Madison, WI; see Supplementary material).

By reducing the TNF- $\alpha$ transcription through $\mathrm{cAMP}$ dependent protein kinases, ${ }^{44}$ rolipram can alleviate inflammations, hence TNF- $\alpha$ plays a key role in proinflammatory processes. In combination with cochlear implants, benefits may be achieved by inhibiting postinsertion inflammation processes.

Our data proves that rolipram penetrates the DC cell membrane and evokes biological responses in this cell type. Conversely, rolipram does not cause a biological reaction in SGC without the support of the tested drug-delivery system LNC. Even if a small amount of pure rolipram can influence neuronal cells, the encapsulation in nanocarriers would be beneficial. As LNC encapsulation of rolipram increases the SGC survival rate and would allow a targeted drug delivery in future, this approach would be economically and clinically beneficial in terms of lower costs for drugs and decreasing side effects.

The positive results of in vitro experiments, which provided the basis for the performed in vivo studies, could not be confirmed in vivo. The comparison between the test substance-treated left ears with the right control ears (PBStreated) revealed no differences in SGC-densities. The only significant difference was shown in the control group, where both sides were inoculated with PBS.

These results might be caused by an additional perilymphatic dilution of the test substances which leads to an ineffective concentration. In future experiments, the neuroprotective effect of a higher dosage of LNC rolipram particles might be examined, although the risk of causing toxic effects on the neuronal cells is a possibility. By administrating high dosages at the base of the cochlea, basal cells could be influenced by the high concentration before the desired dilution is achieved in the whole cochlea volume. Furthermore, a leakage of the injected substances via the ductus perilymphaticus is assumed since a contralateral transfer between treated and untreated cochleae was confirmed..$^{45}$

Another reason for the different results of the in vitro and in vivo study may be the usage of different species of different ages. On the one hand, neonatal rats were used to perform the in vitro culture; on the other hand, adult guinea pigs were used for in vivo studies. Thus, different trophic requirements and receptor expressions for neonatal and adult SGC were presumed, which are likely to differ in the young and adult stage. ${ }^{9}$ The inhomogeneous results might be due to an inadequate trophic support in the adult stage of the in vivo experiment.

Regarding the increased SGC degeneration following the cessation of neurotrophic factors, ${ }^{9}$ a preliminary protection could be assumed for the test substances used in this study. By performing single administration, the neuroprotective effect might be achieved in the first period of the study. The positive effect could be distinguished after the accelerated degeneration, as described by Gillespie and colleagues. ${ }^{9}$ A later experiment could not reproduce the effect of an increased SGC degeneration after cessation of neurotrophic factors, whereas electrical stimulation for hearing threshold measurements was performed, ${ }^{28}$ which themselves have neuroprotective potential. ${ }^{46,47}$

As mentioned before, the only significant difference in SGC density in vivo was detected between the PBS-treated ears of the control group. Considering that the SGC density of both ears should be equal because of equal treatment, one could speculate that the difference is based on an additional trauma due to PBS injection and manipulation that increases the deafness-induced SGC degeneration at the left side. The surgeon's handedness could also be an explanation for this. But the left ears' SGC density was the same as one of the other experimental groups. Additionally, the SGC density of PBStreated right ears of the PBS group was higher than the density of all other PBS-treated right ears of the other experimental groups. Therefore, it is not an increased SGC degeneration in left PBS-treated ears of the control group but a decreased SGC degeneration in right PBS-treated ears of the PBS group. We do not yet have an explanation for this effect.

We were able to demonstrate significantly increased soma diameters of the treated ears in the LNC-FITC group and the rolipram group in vivo. In the LNC-FITC-rolipram group, the SD's soma diameter was relatively wide and, even if the graph (Figure 6B) looks like there may be a significant difference between the treated and nontreated ears of this group, no statistically significant difference was observed. Several previous studies reported an increase of soma diameter after treatment with neurotrophic factors such as BDNF in deafened animals. ${ }^{48,49}$ The underlying mechanisms of the soma diameter increase and the functional impact are not yet known, which complicates a final appraisal of this parameter. 


\section{Conclusion}

This study demonstrates the SGC protective effects of LNCmediated rolipram delivery in vitro in terms of concentration dependent neuronal survival and neurite outgrowth. We hypothesize that this biological effect indirectly demonstrates that the lipidic nanoparticles improve the transport of rolipram through the neuronal cell membrane into the cytoplasm of the neurons where the increase of rolipram and LNC induces significant neuronal protection. Additionally, we were able to demonstrate a strong anti-inflammatory effect of rolipram when cultivated with activated dendritic cells. The LNC rolipram combination presented an anti-inflammatory effect as well, though weaker, which might be due to the release rate of rolipram out of the LNC.

The in vivo study did not confirm the in vitro results, which might be due to either perilymphatic dilution or insufficient duration of drug application.

Even if the in vitro results that we were able to report on could not be confirmed in vivo, we still believe that rolipram is a promising drug for neuronal protection in inner ear therapy and that LNC are a feasible drug-delivery system for treatment of inner ear cells if in vivo methods are modified. Future work has to thoroughly investigate the effect of LNC on SGC and DC, and has to identify the correct LNC/rolipram ratio to cause a biological effect in vivo. Additionally, experiments may be conducted to investigate the effect of $\mathrm{LNC}$ /rolipram on connective tissue proliferation around an implanted device in vivo. Controlled uptake of LNC into cochlear cells should be investigated to decrease the amount of LNC that have to be applied. Nevertheless, at present, LNC are promising tools to deliver drugs to the inner ear since they are non-toxic to the inner ear tissue in vitro and in vivo if applied in sufficient dilution. They also enable the biological effect of rolipram in vitro. This opens the exciting possibility of using these nanoparticles as a drug-delivery system for inner ear structures.

\section{Acknowledgments}

This study was supported by the European Community 6th Framework Programme on Research, Technological Development and Demonstration (Nanotechnology-based Drug Delivery. Contract Number: NMP4-CT-2006-026556, Project acronym: NANOEAR). We would like to thank Dr Henning Voigt, Hannover Medical School, for his support in quality management.

\section{Disclosure}

The authors report no conflict of interest in this work.

\section{References}

1. Selimoglu E. Aminoglycoside-induced ototoxicity. Curr Pharm Des. 2007;13(1):119-126.

2. Yamane H, Nakai Y, Konishi K. Furosemide-induced alteration of drug pathway to cochlea. Acta Otolaryngol Suppl. 1988;447:28-35.

3. Lenarz T. Cochlear implants: what can be achieved? Am J Otol. 1997;18(Suppl 6):S2-S3.

4. Shibata SB, Budenz CL, Bowling SA, Pfingst BE, Raphael Y. Nerve maintenance and regeneration in the damaged cochlea. Hear Res. 2011;281(1-2):56-64.

5. Altschuler RA, Cho Y, Ylikoski J, Pirvola U, Magal E, Miller JM. Rescue and regrowth of sensory nerves following deafferentation by neurotrophic factors. Ann NY Acad Sci. 1999;884:305-311.

6. Incesulu A, Nadol JB Jr. Correlation of acoustic threshold measures and spiral ganglion cell survival in severe to profound sensorineural hearing loss: implications for cochlear implantation. Ann Otol Rhinol Laryngol. 1998;107(11 Pt 1):906-911.

7. Gillespie LN, Shepherd RK. Clinical application of neurotrophic factors: the potential for primary auditory neuron protection. Eur J Neurosci. 2005;22(9):2123-2133.

8. Miller JM, Chi DH, O’Keeffe LJ, Kruszka P, Raphael Y, Altschuler RA. Neurotrophins can enhance spiral ganglion cell survival after inner hair cell loss. Int J Dev Neurosci. 1997;15(4-5):631-643.

9. Gillespie LN, Clark GM, Bartlett PF, Marzella PL. BDNF-induced survival of auditory neurons in vivo: cessation of treatment leads to accelerated loss of survival effects. J Neurosci Res. 2003;71(6): 785-790.

10. Rejali D, Lee VA, Abrashkin KA, Humayun N, Swiderski DL, RaphaelY. Cochlear implants and ex vivo BDNF gene therapy protect spiral ganglion neurons. Hear Res. 2007;228(1-2):180-187.

11. Yagi M, Kanzaki S, Kawamoto K, et al. Spiral ganglion neurons are protected from degeneration by GDNF gene therapy. J Assoc Res Otolaryngol. 2000;1(4):315-325.

12. Han JJ, Mhatre AN, Wareing M, et al. Transgene expression in the guinea pig cochlea mediated by a lentivirus-derived gene transfer vector. Hum Gene Ther. 1999;10(11):1867-1873.

13. Suzuki M, Yamasoba T, Suzukawa K, Kaga K. Adenoviral vector gene delivery via the round window membrane in guinea pigs. Neuroreport. 2003;14(15):1951-1955.

14. Husseman J, Raphael Y. Gene therapy in the inner ear using adenovirus vectors. Adv Otorhinolaryngol. 2009;66:37-51.

15. Kho ST, Pettis RM, Mhatre AN, Lalwani AK. Cochlear microinjection and its effects upon auditory function in the guinea pig. Eur Arch Otorhinolaryngol. 2000;257(9):469-472.

16. Pautler M, Brenner S. Nanomedicine: promises and challenges for the future of public health. Int J Nanomedicine. 2010;5:803-809.

17. Scheper V, Wolf M, Scholl M, et al. Potential novel drug carriers for inner ear treatment: hyperbranched polylysine and lipid nanocapsules. Nanomedicine (Lond). 2009;4(6):623-635.

18. Newbold C, Richardson R, Huang CQ, Milojevic D, Cowan R, Shepherd R. An in vitro model for investigating impedance changes with cell growth and electrical stimulation: implications for cochlear implants. J Neural Eng. 2004;1(4):218-227.

19. Beaumont E, Whitaker CM, Burke DA, Hetman M, Onifer SM. Effects of rolipram on adult rat oligodendrocytes and functional recovery after contusive cervical spinal cord injury. Neuroscience. 2009;163(4):985-990.

20. Whitaker CM, Beaumont E, Wells MJ, Magnuson DS, Hetman M, Onifer SM. Rolipram attenuates acute oligodendrocyte death in the adult rat ventrolateral funiculus following contusive cervical spinal cord injury. Neurosci Lett. 2008;438(2):200-204.

21. Zhu J, Mix E, Winblad B. The antidepressant and antiinflammatory effects of rolipram in the central nervous system. CNS Drug Rev. 2001;7(4):387-398.

22. Krause W, Kuhne G, Sauerbrey N. Pharmacokinetics of (+)-rolipram and (-)-rolipram in healthy volunteers. Eur J Clin Pharmacol. 1990;38(1):71-75. 
23. Heurtault B, Saulnier P, Pech B, Proust JE, Benoit JP. A novel phase inversion-based process for the preparation of lipid nanocarriers. Pharm Res. 2002;19(6):875-880.

24. Beduneau A, Saulnier P, Anton N, et al. Pegylated nanocapsules produced by an organic solvent-free method: Evaluation of their stealth properties. Pharmaceutical Res. 2006;23(9):2190-2199.

25. Lefebvre PP, Malgrange B, Staecker H, Moghadass M, Van de Water TR, Moonen G. Neurotrophins affect survival and neuritogenesis by adult injured auditory neurons in vitro. Neuroreport. 1994;5(8): 865-868.

26. Gillespie LN, Clark GM, Bartlett PF, Marzella PL. LIF is more potent than BDNF in promoting neurite outgrowth of mammalian auditory neurons in vitro. Neuroreport. 2001;12(2):275-279.

27. Lutz MB, Kukutsch N, Ogilvie AL, et al. An advanced culture method for generating large quantities of highly pure dendritic cells from mouse bone marrow. J Immunol Methods. 1999;223(1):77-92.

28. Agterberg MJ, Versnel H, van Dijk LM, de Groot JC, Klis SF. Enhanced survival of spiral ganglion cells after cessation of treatment with brain-derived neurotrophic factor in deafened guinea pigs. JAssoc Res Otolaryngol. 2009;10(3):355-367.

29. Vivero RJ, Joseph DE, Angeli S, et al. Dexamethasone base conserves hearing from electrode trauma-induced hearing loss. Laryngoscope. 2008;118(11):2028-2035.

30. Versnel H, Agterberg MJ, de Groot JC, Smoorenburg GF, Klis SF. Time course of cochlear electrophysiology and morphology after combined administration of kanamycin and furosemide. Hear Res. 2007;231(1-2):1-12.

31. Wefstaedt P, Scheper V, Lenarz T, Stover T. Brain-derived neurotrophic factor/glial cell line-derived neurotrophic factor survival effects on auditory neurons are not limited by dexamethasone. Neuroreport. 2005;16(18):2011-2014.

32. Deree J, Martins JO, Melbostad H, Loomis WH, Coimbra R. Insights into the regulation of TNF-alpha production in human mononuclear cells: the effects of non-specific phosphodiesterase inhibition. Clinics (Sao Paulo). 2008;63(3):321-328.

33. Tao X, Finkbeiner S, Arnold DB, Shaywitz AJ, Greenberg ME. Ca2+ influx regulates BDNF transcription by a CREB family transcription factor-dependent mechanism. Neuron. 1998;20(4):709-726.

34. Wolf M. 3g-Nanotechnology Based Targeted Drug-Delivery Using the Guinea Pig Inner Ear as a Model Target Organ [thesis]. Hannover, Germany: University of Veterinary Medicine; 2009:91-92.

35. Santini MT, Cametti C, Indovina PL, Morelli G, Donelli G. Polylysine induces changes in membrane electrical properties of K562 cells. J Biomedical Mater Res. 1997;35(2):165-174.
36. Zhang Y, Zhang W, Lobler M, et al. Inner ear biocompatibility of lipid nanocapsules after round window membrane application. Int J Pharm. 2011;404(1-2):211-219.

37. Kim BY, Rutka JT, Chan WC. Nanomedicine. $N$ Engl J Med. 2010;363(25):2434-2443.

38. Vonarbourg A, Passirani C, Desigaux L, et al. The encapsulation of DNA molecules within biomimetic lipid nanocapsules. Biomaterials. 2009;30(18):3197-3204.

39. Laverty PH, Leskovar A, Breur GJ, et al. A preliminary study of intravenous surfactants in paraplegic dogs: polymer therapy in canine clinical SCI. J Neurotrauma. 2004;21(12):1767-1777.

40. Koob AO, Colby JM, Borgens RB. Behavioral recovery from traumatic brain injury after membrane reconstruction using polyethylene glycol. J Biol Eng. 2008;2:9.

41. Spoendlin H. Factors inducing retrograde degeneration of the cochlear nerve. Ann Otol Rhinol Laryngol Suppl. 1984;112:76-82.

42. Aglah C, Gordon T, Posse de Chaves EI. cAMP promotes neurite outgrowth and extension through protein kinase A but independently of Erk activation in cultured rat motoneurons. Neuropharmacology. 2008;55(1):8-17.

43. Xu N, Engbers J, Khaja S, Xu L, Clark JJ, Hansen MR. Influence of cAMP and protein kinase A on neurite length from spiral ganglion neurons. Hear Res. 2012;283(1-2):33-44.

44. Heystek HC, Thierry AC, Soulard P, Moulon C. Phosphodiesterase 4 inhibitors reduce human dendritic cell inflammatory cytokine production and Th1-polarizing capacity. Int Immunol. 2003;15(7):827-835.

45. Stoever T, Yagi M, Raphael Y. Cochlear gene transfer: round window versus cochleostomy inoculation. Hear Res. 1999;136(1-2):124-130.

46. Mitchell A, Miller JM, Finger PA, Heller JW, Raphael Y, Altschuler RA. Effects of chronic high-rate electrical stimulation on the cochlea and eighth nerve in the deafened guinea pig. Hear Res. 1997;105(1-2): $30-43$.

47. Chikar JA, Colesa DJ, Swiderski DL, Di Polo A, Raphael Y, Pfingst BE. Over-expression of BDNF by adenovirus with concurrent electrical stimulation improves cochlear implant thresholds and survival of auditory neurons. Hear Res. 2008;245(1-2):24-34.

48. Glueckert R, Bitsche M, Miller JM, et al. Deafferentation-associated changes in afferent and efferent processes in the guinea pig cochlea and afferent regeneration with chronic intrascalar brain-derived neurotrophic factor and acidic fibroblast growth factor. J Comp Neurol. 2008;507(4):1602-1621.

49. McGuinness SL, Shepherd RK. Exogenous BDNF rescues rat spiral ganglion neurons in vivo. Otol Neurotol. 2005;26(5):1064-1072. 


\section{Supplementary material Vitality test}

To determine the vitality of dendritic cells at the end of the experiment (day 10), a CellTiter $96^{\circledR}$ Aqueous One Solution Cell

Table SI Vitality values of dendritic cells after incubation with the test compounds and LPS stimulation; $\mathrm{n}=3$ per substance and concentration

\begin{tabular}{|c|c|c|c|}
\hline Rolipram $0.01 \mu \mathrm{mol}$ & 0.414 & 0.399 & 0.391 \\
\hline Rolipram $0.1 \mu \mathrm{mol}$ & 0.406 & 0.419 & 0.417 \\
\hline Rolipram I $\mu \mathrm{mol}$ & 0.4 & 0.413 & 0.423 \\
\hline Rolipram $10 \mu \mathrm{mol}$ & 0.421 & 0.367 & 0.433 \\
\hline LNC-FITC-rolipram $0.01 \mu \mathrm{mol}$ & 0.502 & 0.399 & 0.416 \\
\hline LNC-FITC-rolipram $0.1 \mu \mathrm{mol}$ & 0.411 & 0.374 & 0.438 \\
\hline LNC-FITC-rolipram I $\mu \mathrm{mol}$ & 0.446 & 0.499 & 0.455 \\
\hline LNC-FITC-rolipram $10 \mu \mathrm{mol}$ & 0.922 & 0.84 & 0.784 \\
\hline LNC-Blank $0.01 \mu \mathrm{mol}$ & 0.497 & 0.482 & 0.476 \\
\hline LNC-Blank $0.1 \mu \mathrm{mol}$ & 0.42 & 0.431 & 0.418 \\
\hline LNC-Blank I $\mu \mathrm{mol}$ & 0.493 & 0.451 & 0.463 \\
\hline LNC-Blank $10 \mu \mathrm{mol}$ & 0.172 & 0.249 & 0.186 \\
\hline LNC-FITC $0.01 \mu \mathrm{mol}$ & 0.497 & 0.422 & 0.396 \\
\hline LNC-FITC $0.1 \mu \mathrm{mol}$ & 0.429 & 0.42 & 0.359 \\
\hline LNC-FITC I $\mu \mathrm{mol}$ & 0.519 & 0.474 & 0.446 \\
\hline LNC-FITC I0 $\mu \mathrm{mol}$ & 0.67 & 0.654 & 0.619 \\
\hline DMSO (vehicle control) & 0.32 & 0.319 & 0.322 \\
\hline LPS (positive control) & 0.518 & 0.465 & 0.444 \\
\hline
\end{tabular}

Notes: Data are shown in relative values and reflect the optical density. High scores correlate with an undisturbed cell vitality. The values of the LNC-FITC $10 \mu \mathrm{mol}$ and LNC-FITC-rolipram $10 \mu \mathrm{mol}$ groups are the highest, even though the cells were certainly destroyed. The influence of the fluorescence marker FITC in this high concentration is responsible for these false positive results.

Abbreviations: DMSO, dimethyl sulfate; FITC, fluorescein isothiocyanate; LNC, lipidic nanocapsules; LPS, lipopolysaccharide.
Proliferation Assay (Promega, Madison, WI) was performed. In addition, the cells were subjected to microscopic inspection to note any morphological differences. This examination allows a trend statement about a possible influence of the test substances. The results of the viability test reveal possible cellular impairments caused by the test substances. Thus, a lower production of tumor necrosis factor- $\alpha$ (TNF- $\alpha$ ) depends not only on the inhibition of cytokine production but also on an increased degeneration of cells. This assay is based on nicotinamide adenine dinucleotide phosphate (NADPH) and nicotinamide adenine dinucleotide (NADH), which catalyzes the conversion of the yellow methyltetrazolium to a violet formazan product. NADPH/NADH are only found in living cells. Consequently, a color change by $490 \mathrm{~nm}$ measured by photometric analysis is an indication of cell vitality. The resulting amount of formazan is directly proportional to the number of viable cells. Supplementary Table 1 shows the measured values.

\section{AABR measurements}

Acoustically evoked auditory brainstem response measurements were performed to determine the hearing threshold of all experimental animals before and after deafening for verification of the procedure's success. Because the used system allows stimulation with a maximum of $90 \mathrm{~dB}$ SPL and all animals' hearing thresholds reached or exceeded that level 7 and 21 days after deafening, the hearing thresholds are plotted at $90 \mathrm{~dB}$ (Supplementary Figure 1).

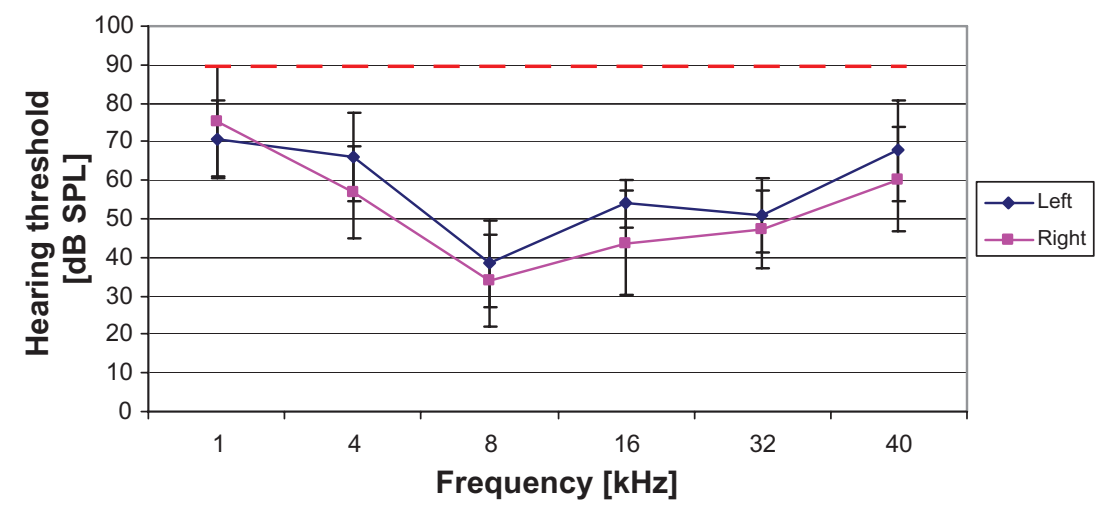

Figure SI By frequency-specific AABR measurements on day 0, a normal hearing threshold was detected in all animals (blue and pink line; mean \pm SD).

Notes: The results of the measurements on day 7 and day 21 are plotted as a red line. None of the animals had residual hearing after the deafening procedure. The hearing threshold of all animals was $90 \mathrm{~dB}$ SPL or above on day 7 and did not recover until the final measurement on day 21 .

Abbreviations: AABR, acoustically evoked auditory brainstem response; SD, standard deviation.

\section{Publish your work in this journal}

The International Journal of Nanomedicine is an international, peerreviewed journal focusing on the application of nanotechnology in diagnostics, therapeutics, and drug delivery systems throughout the biomedical field. This journal is indexed on PubMed Central, MedLine, CAS, SciSearch ${ }^{\circledR}$, Current Contents ${ }^{\circledR} /$ Clinical Medicine,
Journal Citation Reports/Science Edition, EMBase, Scopus and the Elsevier Bibliographic databases. The manuscript management system is completely online and includes a very quick and fair peer-review system, which is all easy to use. Visit http://www.dovepress.com/ testimonials.php to read real quotes from published authors. 